\title{
USO DA MISTURA CARBOXIMETILCELULOSE/SPIRULINA COMO VEÍCULO DE INOCULAÇÃO - EFEITO DA VISCOSIDADE E DA ESTABILIDADE DA MISTURA
}

\author{
C. S. FREITAS ${ }^{1}$, P. J. OLIVEIRA ${ }^{1}$, N. G. RUMJANECK ${ }^{2}$ e G. R. XAVIER ${ }^{2}$ \\ ${ }^{1}$ Universidade Federal Rural do Rio de Janeiro, Departamento de Engenharia Química, Laboratório de \\ Ciência e Tecnologia de Polímeros \\ ${ }^{2}$ Empresa Brasileira de Pesquisa Agropecuária - EMBRAPA \\ E-mail para contato: pjansen@ufrrj.br
}

\begin{abstract}
RESUMO - Nesse trabalho, a mistura Carboximetilcelulose/Spirulina foi investigada no que tange ao seu aspecto reológico e à sua estabilidade dimensional para possíveis aplicações como veículo de inoculação. De modo a avaliar o efeito da Spirulina na composição da mistura, foram preparadas misturas entre $\mathrm{CMC}$ /Spirulina nas composições contendo 2,5\%, $5 \%, 10 \%, 40 \%$ e $50 \%$ de Spirulina em massa. Os testes de estabilidade e a decomposição antes e após a autoclavação das misturas mostraram que as misturas quando autoclavadas não apresentaram separação de fases, indicando uma maior estabilidade dimensional da mistura. As análises viscosimétricas das amostras revelaram um comportamento nãonewtoniano. Além disso, observou-se uma diminuição da viscosidade com o aumento da quantidade de Spirulina na mistura, o que pode contribuir para formulações visando inoculantes líquidos.
\end{abstract}

\section{INTRODUÇÃO}

O veículo mais utilizado para a produção de inoculante é a turfa. No entanto, a composição físico-química da turfa nem sempre a qualifica como um bom veículo, pois dependendo da sua origem, a mesma pode não ter as características necessárias para a sobrevivência das bactérias. Além disso, a turfa não está disponível em alguns países e é um recurso natural não renovável (Schuh, 2005). Para a aplicação tecnológica da turfa, é necessária a esterilização e a refrigeração do material, o que acarreta elevados custos de produção.

Embora haja diferentes tipos de inoculantes no mercado, a procura por novos materiais que possam ser utilizados em substituição à turfa é uma demanda atual. Esses novos materiais devem superar as limitações técnicas de uso da turfa, diminuindo dessa forma, os custos de produção e facilitando a aplicação do produto na semente. Além disso, o novo veículo deve garantir a sobrevivência e a eficiência do rizóbio (bactéria que fixa nitrogênio), ser facilmente esterilizável (autoclave ou radiação), proporcionar boa adesão às sementes, e não ser tóxico às pessoas, animais e plantas (Keyser, 1992), além de ser um material de fonte renovável.

Na busca por novos materiais em substituição à turfa, a Spirulina apresenta-se como um material de grande potencial tecnológico devido as suas características físico-químicas. A Spirulina contém um vasto espectro de nutrientes que inclui proteínas, carboidratos, vitaminas, minerais, pigmentos, antioxidantes, além de oligoelementos. O teor de proteína é muito elevado, correspondendo a 60-70\% do seu peso seco (Cifferi, 1983). Apresenta alta concentração de vitaminas e 4-7\% de lípidios. Os ácidos graxos essenciais, ácido linolênico e também 13,6\% de carboidratos fazem parte da sua composição (Mahajan, 1997; Cohen, 1997). Estas substâncias podem servir como fonte de carbono e nutrientes, apresentando um elevado potencial como veículo de inoculação. Além disso, devido à sua característica estrutural, a Spirulina apresenta boa 
compatibilidade com diversos biopolímeros, podendo ser utilizada em formulações de modo a melhorar algumas de suas propriedades físico-mecânicas, produzindo bons veículos de inoculação.

Neste contexto, a carboximetilcelulose (CMC) tem se mostrado um polímero bastante promissor na preparação de misturas poliméricas, misturas entre CMC/amido, para aplicação tecnológica como veículo de inoculação (Rhor, 2007; Fernandes Júnior et al., 2009).

Este trabalho tem como objetivo avaliar o potencial da mistura Carboximetilcelulose/Spirulina como veículo de inoculação. Para isso, nesta primeira etapa foram realizados testes viscosimétricos e de estabilidade dimensional (visual e olfativo).

\section{MATERIAIS E METÓDOS}

\subsection{Materiais}

Foi utilizada nesta pesquisa a Spirulina, uma cianobactéria conhecida cientificamente como Arthrospira platensis, conforme mostra a figura 1. A Spirulina desidratada de procedência da Brasil Vital® foi mantida ao abrigo da luz e umidade até a sua utilização.

O polímero utilizado foi o Carboximetilcelulose de Sódio (CMC) de média viscosidade (2000-3000) da marca Quimesp.

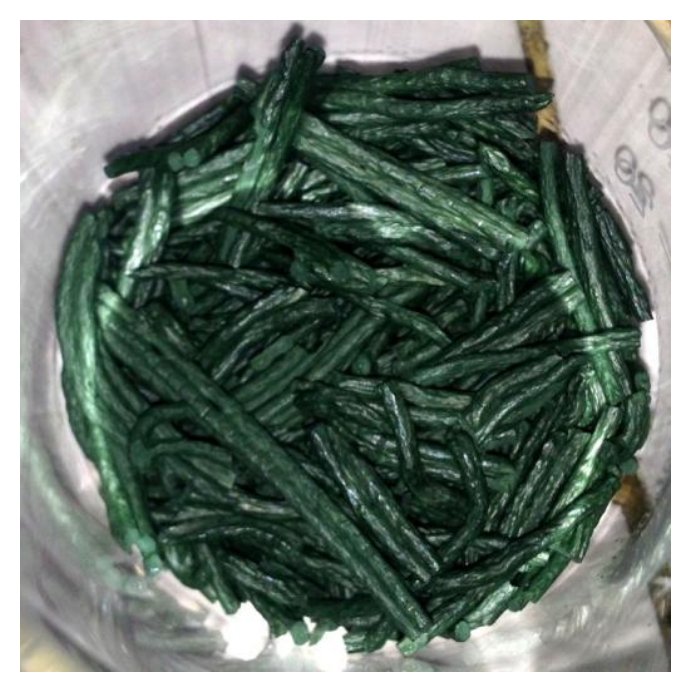

Figura 1 - Spirulina

\subsection{Métodos}

As misturas de CMC/Spirulina foram feitas nas concentrações de 50\%, 40\%, 10\%, 2,5\% e 5\% em massa de Spirulina, com quatro repetições.

\section{Teste de Estabilidade}

Parte da mistura foi armazenada em temperatura ambiente e outra parte foi armazenada sob refrigeração controlada. Uma parte (parte 1) da amostra foi condicionada em tubos do tipo Falcon e foi autoclavada para eliminar possíveis contaminantes, enquanto a outra parte (parte 2) foi condicionada em garrafas de $200 \mathrm{~mL}$ e não foi autoclavada. 


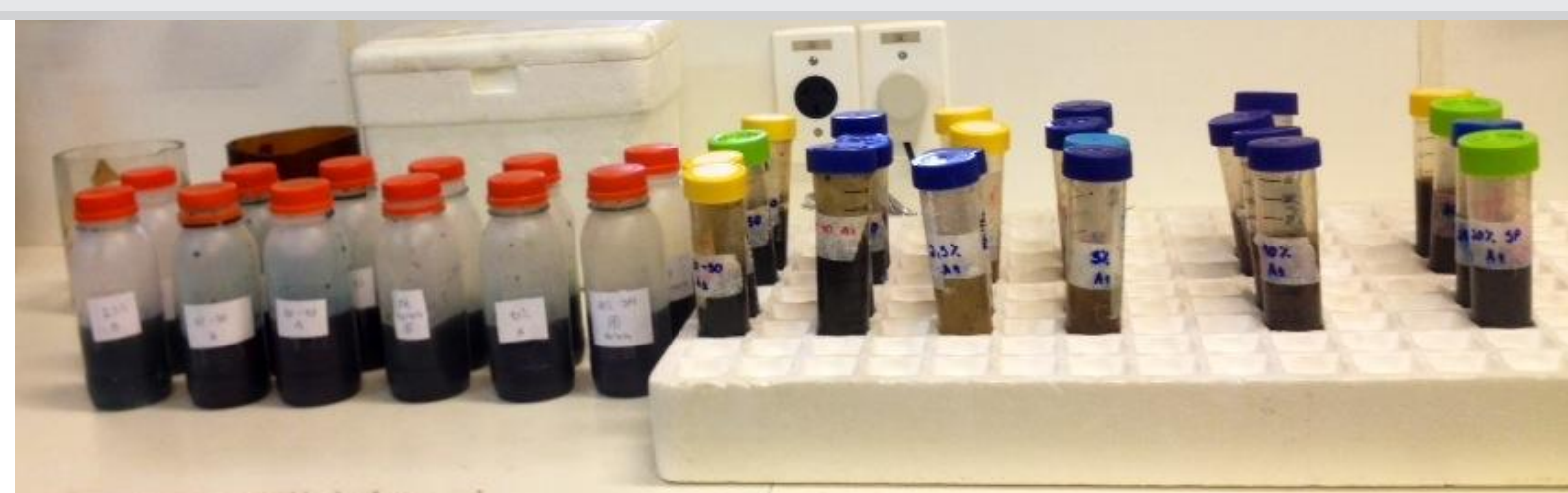

Figura 2 - Parte 1 (dir.) amostras autoclavadas e parte 2 (esq.) amostras não autoclavadas.

A análise visual e olfativa foi realizada durante 8 dias, a fim de avaliar a estabilidade e decomposição da mistura, bem como a influência da descontaminação devido ao uso da autoclave.

$\mathrm{O}$ pH das amostras foi verificado após o $7^{\circ}$ dia de incubação das amostras.

Foi realizado análise viscosimétrica das amostras $\mathrm{CMC}$ /Spirulina, utilizando um viscosímetro do tipo Brookfield DV-III Ultra Programmable Rheometer e com spindle modelo LV3, com temperatura de $45^{\circ} \mathrm{C}$ e velocidade de 0,1 a $250 \mathrm{rpm}$.



Figura 3- Brookfield DV-III Ultra Programmable Rheometer

Devido à alta viscosidade, a misturas com concentração de $2,5 \%, 5 \%$ e $10 \%$ foram diluídas com água Milli-Q. Pegou-se $10 \mathrm{~g}$ de cada amostra e adicionou-se $20 \mathrm{~mL}$ de água Milli-Q, exceto nas amostras de 2,5\%, onde foram adicionados $30 \mathrm{~mL}$ de água Milli-Q. Posteriormente, as misturas foram agitadas no Vortex até atingirem a homogeneidade.

As misturas foram colocadas no banho à $70^{\circ} \mathrm{C}$ durante uma hora antes da realização do teste.

\section{RESULTADOS E DISCUSSÃO}

\section{$\underline{\text { Análise Visual e Olfativa das amostras }}$}

As amostras foram analisadas diariamente durante um período de 8 dias a fim de investigar a sua estabilidade dimensional, separação de fases. Os resultados de estabilidade dimensional das 
misturas mostraram que todas as amostras autoclavadas não apresentaram separação de fases, indicando uma boa estabilidade dimensional da amostra, tampouco mudança de odor. No entanto, como mostrado na figura 4, observou-se uma mudança na coloração de todas as amostras que foi atribuída à alteração química dos pigmentos como a ficocianina durante o processo de autoclavação. Edwards et al. (1997) mostrou que entre 60 e $70^{\circ} \mathrm{C}$ ocorre a desnaturação da ficocianina.

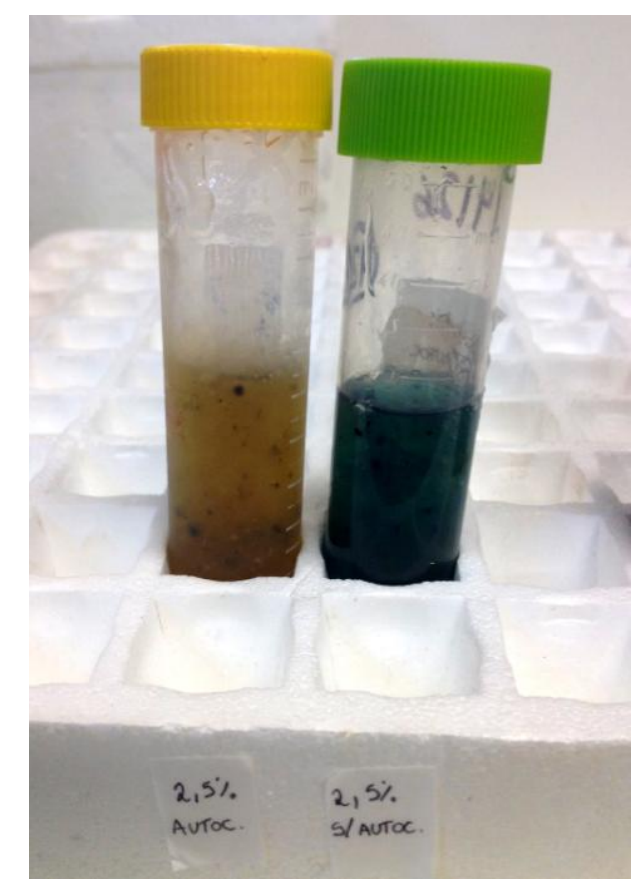

Figura 4 - Amostra autoclavada (esq) e amostra não autoclavada (dir.).

Para as amostras não autoclavadas, os resultados mostraram que, a partir do $3^{\circ}$ dia, as amostras contendo 60/40 e 50/50\% CMC/Spirulina apresentaram separação de fases, sugerindo a ocorrência de decomposição da amostra. Enquanto que as amostras de 2,5\%, 5\% e 10\%, mostraram sinais de separação de fases somente a partir do $5^{\circ}$ dia. Esse resultado pode ser atribuído à baixa quantidade de Spirulina presente na amostra. As amostras 60/40 e 50/50\%, não autoclavadas e armazenadas em geladeira começaram a se decompor a partir do $5^{\circ}$ dia. Este resultado indica que a conservação em baixas temperaturas diminui a decomposição da amostra. Por outro lado, as amostras de 2,5\%, $5 \%$ e $10 \%$, nas mesmas condições, começaram a se decompor a partir do $6^{\circ}$ dia. Essa decomposição foi observada através de separação de fase e mudança cheiro.

\section{Verificacão do pH}

Após sete dias de incubação das misturas foi verificado o $\mathrm{pH}$, que se manteve entre 6 e 7 para todas as amostras. Este resultado é interessante uma vez as bactérias utilizadas como inoculante sobrevivem nesta faixa de $\mathrm{pH}$.

\section{Teste viscosimétrico}

As figuras 6 e 7 mostram os resultados das análises viscosimétricas das amostras de CMC/Spirulina. De um modo geral, nota-se que o aumento da quantidade de Spirulina na mistura promove uma diminuição da viscosidade. Na Figura 6, observa-se uma diminuição da viscosidade com o aumento da velocidade (cisalhamento). Este comportamento reológico é típico de fluidos pseudoplásticos. 


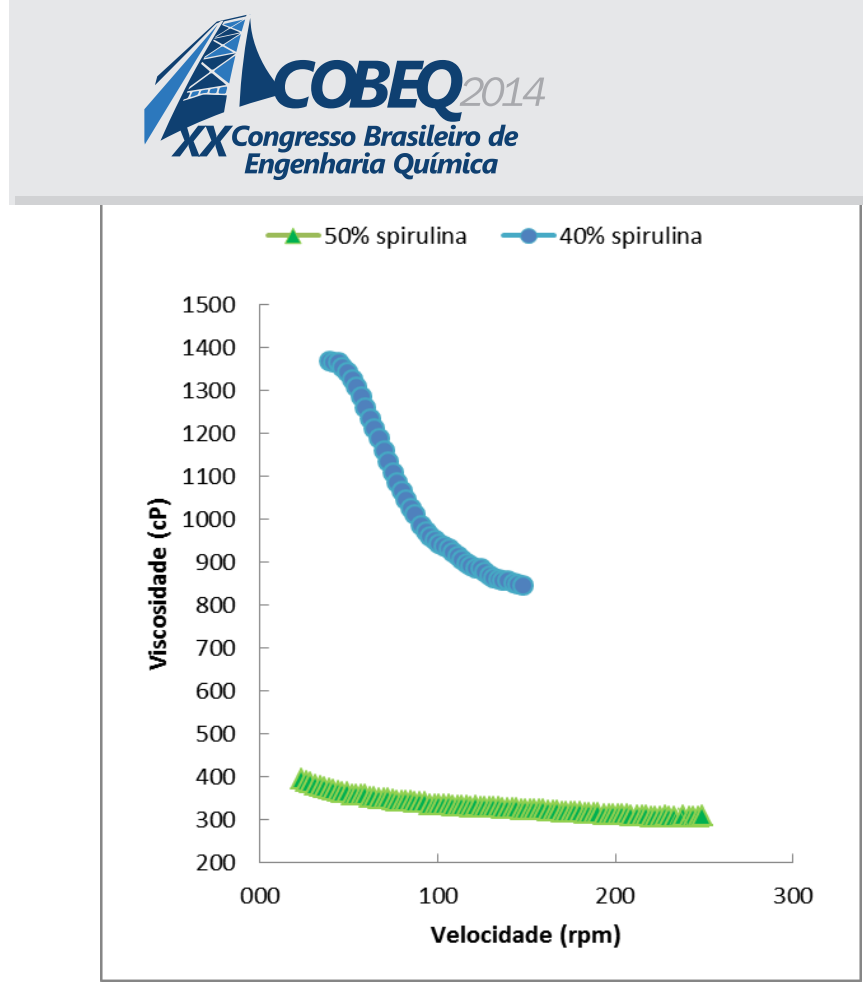

Figura 5 - Viscosidade das amostras 60/40 e $50 / 50 \%$ (CMC/Spirulina) à $45^{\circ} \mathrm{C}$.
19 a 22 de outubro de 2014

Florianópolis/SC

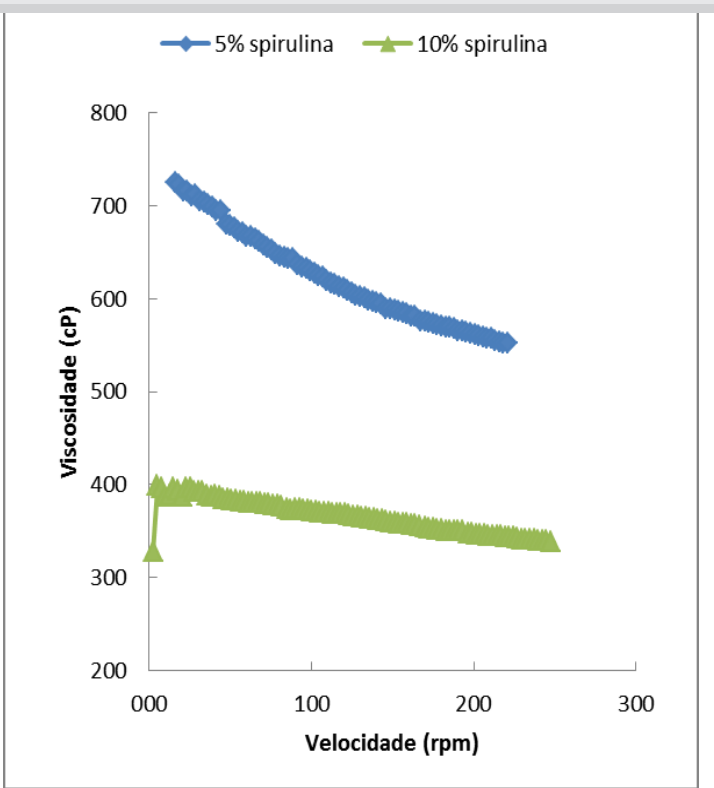

Figura 6- Viscosidade das amostras 50/50 e $50 / 50 \%$ (CMC/Spirulina) à $45^{\circ} \mathrm{C}$.

Comparando o formato das curvas reológicas obtidas para as amostras contendo 50 e $40 \%$ de Spirulina, verifica-se que o aumento da quantidade de Spirulina desloca a curva reológica para uma tendência mais newtoniana, sugerindo a existência de diferentes tipos de interações entre as cadeias poliméricas do CMC e da Spirulina.

Na figura 6, observa-se também uma diminuição da viscosidade com o aumento do teor de Spirulina na mistura. Da mesma forma que nas composições ricas em Spirulina, na figura 5, observa-se um comportamento reológico pseudoplástico.

\section{CONCLUSÃO}

Os resultados de estabilidade dimensional mostraram que é possível a obtenção de misturas sem separação de fases através da autoclavação das amostras, o que contribuirá para uma maior sobrevivência das células quando da preparação do inoculante.

Os resultados das análises viscosimétricas mostraram que a presença de Spirulina torna a mistura menos viscosa, entretanto, as misturas continuam a apresentar comportamento pseudoplástico. Este comportamento reológico é importante para manutenção das propriedades e para aplicações tecnológicas de inoculantes líquidos ou em gel.

Com base no exposto, resultados obtidos neste trabalho permitem concluir que a mistura CMC/Spirulina apresenta um potencial para ser utilizada como veículo de inoculação.

\section{REFERÊNCIAS}

CIFFERI, O. Spirulina, the edible microorganism. Microbiological Rev., 47: 551-578, 1983.

COHEN, Z. The chemicals of Spirulina In:Vonshak,A.,Ed.Spirulina platensis (Arthrospira): 
Physiology, Cell Biology and Biotechnology. Taylor and Francis, London, pp: 175-204. 1997.

EDWARDS, M.R.; HAUER, C.; STACK, R. F.; EISELE, L.E.; MACCOLL, R. Thermophilic Cphycocyanin: effect of temperature, monomer stability and structure. Biochimica et Biophysica ACTA, v.1321, p. 157-164, 1997.

FERNANDES JÚNIOR, P. I. Composiç̃es poliméricas a base de carboximetilcelulose (CMC) e amido como veículos de inoculação de rizobio em leguminosas. Dissertação. (Mestrado em Ciências do Solo) - Universidade Federal Rural do Rio de Janeiro. Seropédica, RJ, 43 f.2006.

KEYSER, H.H. et al. Rhizobial ecology and technology. In: METTING, F.B. (Ed)

Soil Microbial Ecology: Applications in Agricultural and Environmental Management, New York: Marcel Decker, p. 205 - 226, 1992.

MAHAJAN, G.; KAMAT, M. G-linolenic acid production from S.platensis. Appl. Microbiol. Biotechnol., 43: 466-469, 1995.

RHOR, T.G. Estudo reológico da mistura carboximetilcelulose/amido e sua utilização como veículo de inoculação bacteriano.124p. Dissertação (Mestrado) Universidade Federal Rural do Rio de Janeiro, Seropédica, 2007.

SCHUH, C.A. Biopolímeros como suporte para inoculantes. Dissertação de Mestrado, Programa de Pós-Graduação em Microbiologia Agrícola e do Ambiente, Faculdade de Agronomia, Universidade Federal do Rio Grande do Sul. Porto Alegre, RS, Brasil. (81p.). 2005. 